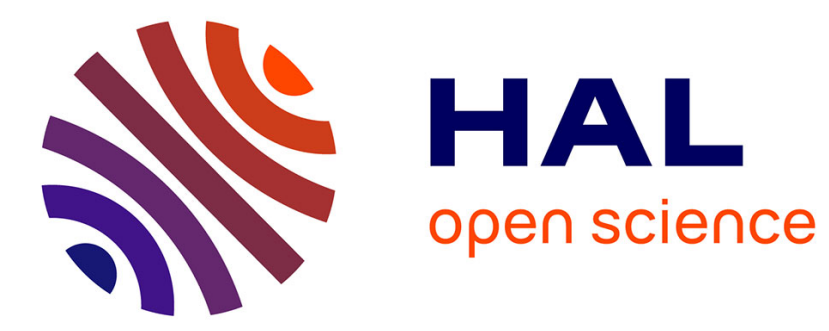

\title{
Copper complexation by fulvic acid affects copper toxicity to the larvae of the polychaete
} Jian-Wen Qiu, Xiao Tang, Chuanbo Zheng, Yan Li, Yanliang Huang

\section{To cite this version:}

Jian-Wen Qiu, Xiao Tang, Chuanbo Zheng, Yan Li, Yanliang Huang. Copper complexation by fulvic acid affects copper toxicity to the larvae of the polychaete. Marine Environmental Research, 2007, 64 (5), pp.563. 10.1016/j.marenvres.2007.06.001 . hal-00562983

\section{HAL Id: hal-00562983 https://hal.science/hal-00562983}

Submitted on 4 Feb 2011

HAL is a multi-disciplinary open access archive for the deposit and dissemination of scientific research documents, whether they are published or not. The documents may come from teaching and research institutions in France or abroad, or from public or private research centers.
L'archive ouverte pluridisciplinaire HAL, est destinée au dépôt et à la diffusion de documents scientifiques de niveau recherche, publiés ou non, émanant des établissements d'enseignement et de recherche français ou étrangers, des laboratoires publics ou privés. 


\section{Accepted Manuscript}

Copper complexation by fulvic acid affects copper toxicity to the larvae of the polychaete Hydroides elegans

Jian-Wen Qiu, Xiao Tang, Chuanbo Zheng, Yan Li, Yanliang Huang

PII:

S0141-1136(07)00072-4

DOI:

10.1016/j.marenvres.2007.06.001

Reference:

MERE 3125

To appear in:

Marine Environmental Research

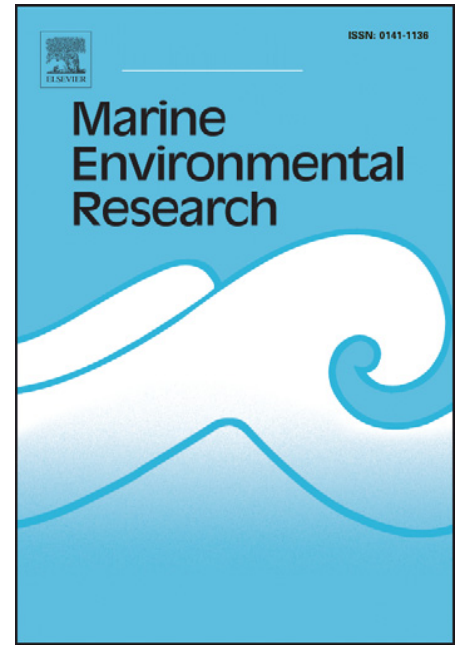

Received Date: $\quad 9$ October 2006

Revised Date: $\quad 10$ February 2007

Accepted Date: $\quad 9$ June 2007

Please cite this article as: Qiu, J-W., Tang, X., Zheng, C., Li, Y., Huang, Y., Copper complexation by fulvic acid affects copper toxicity to the larvae of the polychaete Hydroides elegans, Marine Environmental Research (2007), doi: 10.1016/j.marenvres.2007.06.001

This is a PDF file of an unedited manuscript that has been accepted for publication. As a service to our customers we are providing this early version of the manuscript. The manuscript will undergo copyediting, typesetting, and review of the resulting proof before it is published in its final form. Please note that during the production process errors may be discovered which could affect the content, and all legal disclaimers that apply to the journal pertain. 
Copper complexation by fulvic acid affects copper toxicity to the larvae of the polychaete Hydroides elegans

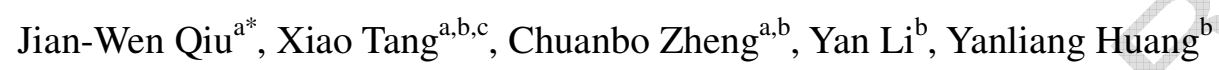

a. Department of Biology, Hong Kong Baptist University, Hong Kong, P.R. China

b. Institute of Oceanology, Chinese Academy of Sciences, Qingdao, Shandong, P.R.

\section{China}

c. Current address: Department of Marine Chemistry, Ocean University of China,

Qingdao, Shandong, P.R. China

* Corresponding author. Phone: 852-34117055; fax: 852-34115995; e-mail: qiujw@ @kbu.edu.hk 


\section{Abstract}

2 Copper toxicity is influenced by a variety of environmental factors including dissolved

3 organic matter (DOM). We examined the complexation of copper by fulvic acid (FA),

4 one of the major components of DOM, by measuring the decline in labile copper by

5 anodic stripping voltammetrically (ASV). The data were described using a one-site

6 ligand binding model, with a ligand concentration of $0.19 \mu \mathrm{mol}$ site $\mathrm{mg}^{-1} \mathrm{C}$, and a $\log K^{\text {' }}$

7 of 6.2 . The model was used to predict labile copper concentration in a bioassay

8 designed to quantify the extent to which $\mathrm{Cu}-\mathrm{FA}$ complexation affected copper toxicity to

9 the larvae of marine polychaete Hydroides elegans. The toxicity data, when expressed

10 as labile copper concentration causing abnormal development, were independent of FA

11 concentration and could be modeled as a logistic function, with a $48-\mathrm{h} \mathrm{EC}_{50}$ of $58.9 \mathrm{~kg} \mathrm{l^{-1 }}$.

12 However, when the data were expressed as a function of total copper concentration, the

13 toxicity was dependent on FA concentration, with a 48-h $\mathrm{EC}_{50}$ ranging from $55.6 \mathrm{~g} \mathrm{l}^{-1}$ in

14 the no-FA control to $137.4 \mathrm{~g}^{-1}$ in the $20 \mathrm{mg} \mathrm{l}^{-1}$ FA treatment. Thus, FA was protective

15 against copper toxicity to the larvae, and such an effect was caused by the reduction in

16 labile copper due to $\mathrm{Cu}-\mathrm{FA}$ complexation. Our results demonstrate the potential of ASV

17 as a useful tool for predicting metal toxicity to the larvae in coastal environment where

18 DOM plays an important role in complexing metal ions. 
1 Keywords: Copper; Speciation; Toxicity, Larvae; Fulvic acid; DOM

\section{1. Introduction}

3 Copper is an essential micronutrient for aquatic animals, but can cause toxic effects at

4 elevated concentrations (White \& Rainbow, 1985). Background copper concentration in

5 marine surface water is usually low $(0.03$ to $0.23 \mu \mathrm{g} / \mathrm{L})$, but can be very high $(>100 \mu \mathrm{g} / \mathrm{L})$

6 in coastal areas severely affected by human activities (Bowen, 1985). Copper toxicity is

7 influenced by a number of environmental factors, such as salinity, $\mathrm{pH}$, particulate organic

8 matter (POM) and dissolved organic matter (DOM) (Campbell, 1995; Allen \& Hansen,

9 1996). The concentration of DOM in natural water is typically measured as dissolved

10 organic carbon (DOC) (Stevenson, 1982). Humic substances are the most important

11 components of DOM, which may constitute from 30 to $90 \%$ of DOC in the aquatic

12 environment (Thurman, 1985). Humic substances are biogenic refractory

13 macromolecules with functional groups such as carboxylic, phenolic, alcoholic and

14 amino groups linked in a complex branching pattern (Stevenson, 1982). These

15 functional groups react with metal ions in the water, and the binding strength to these

16 different types of ligands determines the complexation characteristics of DOM

17 (Stevenson, 1982; Turner, Varney, Whitfield, Mantoura, \& Riley, 1986). Such binding

18 reduces the concentration of free metal ions, which, according to the free-ion activity 
1 model (FIAM), are the most biologically available and thus toxic form of the metals to

2 aquatic organisms (Morel, 1983).

3 However, in a review of metal speciation - bioavailability relationship, Campbell

4 (1995) found only seven studies that had quantitatively related the responses of aquatic

5 organisms to free-metal ion activities in the presence of DOM; of these, three conformed

6 to the FIAM and four deviated from the FIAM. Many more recent studies of metal

7 bioavailability - DOM relationship are also divided into those supporting the FIAM (Kim,

8 Ma, Allen, \& Cha, 1999; Ma, Kim, Cha, \& Allen, 1999; Van Ginneken, Bervoets, \& Blust,

9 2001; Lorenzo, Nieto, \& Beiras, 2002; Wang, Huang, \& Liu, 2002) and those indicating

10 direct interaction between DOM and organisms (Roy \& Campbell, 1997; Voets, Bervoets,

$11 \&$ Blust, 2004). To account for these and other exceptions to the FIAM, Santore, Di

12 Toro, Paquin, Allen, \& Meyer (2001) proposed the biotic ligand model (BLM), which

13 predicts metal toxicity based on the amount of metal accumulated at presumptive binding

14 sites on biological surfaces, such as fish gills, in aquatic organisms. The BLM has been

15 successfully applied to a variety of freshwater organisms such as cladocerans and fish (Di

16 Toro, Allen, Bergman, Meyer, Paquin, \& Santore, 2001; Zhou, Nichols, Playle, \& Wood,

17 2005), amphipods (Borgmann, Nowierski, \& Dixon, 2005), earthworms (Steenbergen,

18 Iaccino, Dewinkel, Reijnders, \& Peijnenburg, 2005) and algae (De Schamphelaere, 
1 Stauber, Wilde, Markish, Brown, Franklin et al., 2005).

2 Marine invertebrate larvae have also been widely used to assess the toxicity of

3 environmental samples because of the environmental relevancy, high sensitivity and low

4 cost (Chapman, Denton, \& Lazorchak, 1995; His, Beiras, \& Seaman, 1999). However,

5 the relationship between metal speciation in the presence of humic substances and the

6 toxic effects to marine organisms has been studied only in few instances (Lorenzo et al.,

7 2002; Rivera-Duarte, Rosen, Lapota, Chadwick, Kear-Padilla, \& Zirino, 2005; Stauber,

8 Andrade, Ramirez, Adams, \& Correa, 2005). Therefore there are scarce data to assess

9 the applicability of the FIAM and BLM as regulatory tools to predict metal toxicity to

10 coastal organisms. In this study, we examined the complexation of copper by fulvic

11 acid (FA) using anodic stripping voltammetry (ASV), and determined how the

12 complexation affected acute toxicity of copper to the larvae of $H$. elegans. Fulvic acid

13 can account for up to $90 \%$ of dissolved humic substances in coastal waters (Porta \&

14 Ronco, 1993) and forms complexes with copper (Stevenson, 1982; Newell \& Sanders,

15 1986). ASV labile copper, which includes cupric ion and inorganically bound copper

16 (Florence, 1986), has been shown to correlate well with cupric ion concentration (Allen

17 \& Hansen, 1996; Lorenzo, Beiras, Mubiana, \& Blust, 2005; Rivera-Duarte et al., 2005)

18 and considered to be the bioavailable fraction of the metal (Florence, 1986). H. elegans 
1 is a serpulid polychaete worm ubiquitous in tropical and subtropical coastal communities.

2 The larvae of this polychaete are as sensitive as echinoderm and mollusk larvae to copper

3 stress (His et al., 1999; Xie et al., 2005) and are available throughout the year for use in

4 monitoring of water quality in tropical and subtropical waters. The larvae of another

5 species of serpulid polychaete (Galeolaria caespitosa), also sensitive to copper, have

6 been successfully used for this purpose in Australia (Ross \& Bidwell, 2001). The result

7 of this study may help us understand the binding between FA and copper in seawater, and

8 how such binding affects the toxicity of dissolved copper to a species of this widely

9 distributed taxon of coastal animals.

10 2. Materials and Methods

11 2.1. Reagents

12 Standard copper solution (Orion ionplus ${ }^{\mathrm{TM}} 0.1 \mathrm{M}$ cupric nitrate) was purchased from

13 Thermo Electron. Fulvic acid (FA) reference material (Suwannee River 1R101F, 1 g FA

$14=0.5304 \mathrm{~g} \mathrm{C}$ ) was purchased from International Humic Substances Society. All other

15 chemicals used were of analytical grade. All solutions were prepared with Milli- $\mathrm{Q}^{\mathrm{TM}}$

16 water. Glass and polypropylene containers were soaked in $10 \% \mathrm{HCl}$, rinsed with

17 Milli-Q water, and dried in an oven before use. Experiments were conducted at $23 \pm 1{ }^{\circ} \mathrm{C}$

18 in artificial seawater $(\mathrm{ASW})(34 \mathrm{psu}, \mathrm{pH}=8.1)$ prepared according to a recipe in Lorenzo 
1 et al. (2002). The background copper content, as measured by differential pulse anodic

2 stripping voltammetry (DPASV) using the standard additions method (Harvey, 2000),

3 was $1.1 \pm 0.3 \operatorname{lg~}^{-1}(\mathrm{n}=3)$.

4 2.2. $C u-F A$ complexation model

5 A two-factor experiment was conducted to determine the conditional stability constant

6 and binding capacity for the $\mathrm{Cu}-\mathrm{FA}$ binding reaction. The purpose was to determine if

7 we could use these binding constants and total copper concentration to predict labile

8 copper concentration. FA stock solution $\left(0.2 \mathrm{~g} \mathrm{l}^{-1}\right)$ was prepared by dissolving the FA

9 reference material in Milli- $\mathrm{Q}^{\mathrm{T}}{ }_{\mathrm{w}}$ ater, and stored at $4{ }^{\circ} \mathrm{C}$ in darkness to prevent

10 photodegradation. Copper stock solution $\left(10 \mathrm{mg} \mathrm{l}^{-1}\right)$ was prepared by pipetting

11 appropriate amount of standard copper solution into ASW. Seventy five sets of copper

12 solution, i.e. a combination of 5 fulvic acid concentrations ranging from 0 to $64 \mathrm{mg} \mathrm{l}^{-1} \mathrm{x}$

1315 copper concentrations ranging from 16 to $256 \mathrm{~g} \mathrm{l}^{-1}$, were prepared by mixing

14 appropriate amounts of fulvic acid and copper stocks. The highest copper concentration

15 used in this study was approximately 4 times the $48-\mathrm{h}_{50}$, as determined previously

16 under identical conditions (Wong, Wong, Shiu, \& Qiu, 2006). The range of fulvic acid

17 concentrations used covered that encountered by coastal animals (Buffle, 1984). The

18 solutions were prepared in 50-ml volumetric flasks and kept in darkness for at least $24 \mathrm{~h}$ 
1 to allow the complexation reaction to reach equilibrium. Copper concentrations were

2 measured by DPASV. Labile copper was determined in the non-acidified sample,

3 whereas total copper was determined after sample acidification with $\mathrm{HNO}_{3}$ and $\mathrm{UV}$

4 irradiation (Florence, 1986). Measurements were taken with a hanging mercury drop

5 electrode, an $\mathrm{Ag} / \mathrm{AgCl}$ reference electrode and an auxiliary platinum electrode connected

6 to a Metrohm 694 VA stand coupled with a Metrohm 693 VA processor. Samples were

7 stirred at $3000 \mathrm{rpm}$ and degassed by nitrogen for $5 \mathrm{~min}$ before measurement. The

8 scanning was performed from $-500 \mathrm{mV}$ to $0 \mathrm{mV}$ at a sweep rate of $6.67 \mathrm{mV} \mathrm{s}^{-1}$ and an

9 increment step of $2 \mathrm{mV}$. The measured potential was $-170 \mathrm{mV} \pm 35 \mathrm{mV}$ and the

10 deposition time was $60 \mathrm{~s}$. Three polarograms were recorded for each solution and the

11 mean peak height was used to calculate labile copper concentration.

12 Scatchard plot (Motulsky \& Christopoulos, 2003) was used to visualize the binding

13 characteristics. The $\mathrm{X}$ axis is bound copper concentration and the $\mathrm{Y}$ axis is bound

14 copper concentration divided by labile copper concentration. The plot will be linear in

15 the presence of one class of binding sites, otherwise it will be curved (Van Ginneken et al.,

16 2001). Depending on the shape of the plot, the data of copper binding by FA were

17 described by a complexation model which assumes either one (Buffle, 1984; Lund,

18 Helbak, \& Seip, 1990) or two (Ma et al., 1999) classes of ligand and a reaction 
1 stoichiometry of 1:1:

2

$$
[\mathrm{CuL}]=\sum_{1}^{\mathrm{n}} \frac{\left[\mathrm{L}_{\mathrm{i}}\right]_{\mathrm{T}} \times K_{\mathrm{i}}^{\prime} \times\left[\mathrm{Cu}^{\prime}\right]}{1+K_{\mathrm{i}}^{\prime} \times\left[\mathrm{Cu}^{\prime}\right]}
$$

3 where $[\mathrm{CuL}]$ is bound copper concentration and $\left[\mathrm{Cu}^{\prime}\right]$ is labile copper concentration.

4 The conditional stability constant(s) $K_{\mathrm{i}}{ }^{\prime}$ and ligand concentration(s) $\left[\mathrm{L}_{\mathrm{i}}\right]_{\mathrm{T}}$ can be

5 calculated through nonlinear regression (Motulsky \& Christopoulos, 2003).

$6 \quad$ 2.3. Bioassays

7 Adult H. elegans were collected between August and November 2005 and in May 2006

8 from the underside of styrofoam floats previously placed into the water of a fish farm in

9 Sai Kung, Hong Kong (22 $19^{\prime}$ N, 114²' E). They were brought to the laboratory at

10 Hong Kong Baptist University (HKBU) where they were reared in aerated seawater

11 aquaria. The procedures for obtaining gametes and performing artificial fertilization

12 had been described in Qiu \& Qian (1997) and Pechenik \& Qian (1998). Fertilized eggs

13 were incubated for $24 \mathrm{~h}$ to allow for development into trochophore larvae. Larvae were

14 concentrated using a sieve of $35 \mu \mathrm{m}$ pore size, and then transferred into the exposure

15 solution using a micropipette.

16 Two separate bioassays were performed to determine the toxicity of fulvic acid and

17 copper to $H$. elegans larvae. The preparation of exposure solutions was identical to that 
1 in section 2.2. The bioassays were performed in 6-well Iwaki Thpolystyrene culture plates.

2 In the first bioassay, the toxicity of FA was examined by exposing the larvae to a series of

3 FA concentrations $\left(0,8,16,32,64,128,256 \mathrm{mg} \mathrm{l}^{-1}\right)$ prepared by mixing FA stock

4 solution and ASW. In the second bioassay, the toxicity of $\mathrm{Cu}-\mathrm{FA}$ solution was

5 determined in a combination of 4 fulvic acid concentrations $\left(0,5,10,20 \mathrm{mg} \mathrm{l}^{-1}\right) \times 12$

6 copper concentrations ( 0 to $362 \mathrm{~kg}^{-1}$ ). There were two replicates in the first bioassay

7 and four replicates in the second bioassay. Each replicate consisted of 20 to 30 larvae in

8 a $10 \mathrm{ml}$ solution. The data were used to calculate overall percentage of abnormal larvae

9 in each treatment.

10 The relationship between percentage of abnormal larvae (Y) and total or labile copper

11 concentration $(\mathrm{X})$ was expressed using a logistic model (Motulsky \& Christopoulos,

12 2003):

$13 \quad \mathrm{Y}=\mathrm{B}+\frac{\mathrm{A}-\mathrm{B}}{1+10^{\mathrm{C}\left(\log \mathrm{EC}_{50}-\mathrm{X}\right)}}$,

14 where $\mathrm{A}$ is the maximum response, $\mathrm{B}$ the baseline response and $\mathrm{C}$ the slope. The

15 difference in $\log \mathrm{EC}_{50}$ between the FA treatments and the no-FA control was determined

16 using $F$ test, which compares the goodness-of-fit of the two models with adjustment for

17 differences in degrees of freedom (Motulsky \& Christopoulos, 2003).

\section{3. Results}


1

2

3 concentration in the exposure solution. It is clear that, in each total copper

4 concentration treatment, labile copper concentration declined with increasing FA

5 concentration. However, the magnitude of decline depended on FA and total copper

6 concentration. At the lowest FA concentration tested $\left(8 \mathrm{mg} \mathrm{l}^{-1}\right),\left[\mathrm{Cu}^{\prime}\right]$ ranged from $82 \%$

7 of total copper at $256 \mathrm{~g} \mathrm{Cu}^{-1}$ to $39 \%$ of total copper at $16 \mathrm{~g} \mathrm{Cu} \mathrm{g}^{-1}$. At $64 \mathrm{mg} \mathrm{l}^{-1} \mathrm{FA}$,

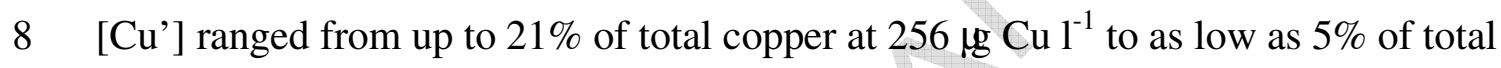

9 copper at $16 \mathrm{~g} \mathrm{Cu} \mathrm{l}^{-1}$. Fig. 1B is the Scatchard plot showing the characteristics of the

10 Cu-FA binding. For each of the four FA treatments, the relationship between [CuL] and

$11[\mathrm{CuL}] /\left[\mathrm{Cu}^{\prime}\right]$ appeared linear, indicating there was one class of dominant binding sites

12 under the experimental conditions.

13 Hence, we fitted the data to a one-site binding model, i.e. $\mathrm{n}=1$ in $\mathrm{Eq}(1)$. The

14 conditional stability constants and ligand concentrations are shown in Table 1. The

15 fitting parameters differed slightly among the FA treatments, with an increase in $\log K^{\prime}$

16 and decrease in [L] with increasing FA concentration. The 95\% confidence interval

17 (C.I.) for each fitting parameter was very small and the coefficient of determination $\left(r^{2}\right)$

18 was high, indicating the model was adequate in describing the binding reaction. 
1 Moreover, when data for all FA treatments were pooled and the non-linear procedure

2 applied, the $95 \%$ C.I. for each fitting parameter was still quite small, and the $r^{2}$ was

3 reasonably high (Table 1), indicating the model could be used to describe the $\mathrm{Cu}-\mathrm{FA}$

4 binding reaction within the wide range of FA concentrations used. Based on the model

5 prediction, a curve describing the relationship between [Cu'] and [CuL] was plotted in

6 Fig. 2. Deviation of the predicted curve from the measured values was minimal.

7 Furthermore, deviation from the model prediction was checked by plotting measured vs.

8 predicted [Cu'] (Fig. 3). The two sets of data showed a good linear correlation, with an

$9 \quad r^{2}$ of 0.97

10 3.2. Bioassays

11 In the first bioassay that tested the toxicity of FA to the polychaete larvae, the

12 percentage of abnormal larvae at the end of the 48-h exposure ranged from 3 to 8 , and

13 was independent of the FA concentration within the test range $\left(0\right.$ to $\left.256 \mathrm{mg} \mathrm{l}^{-1}\right)$. Thus,

14 FA itself was not toxic to the larvae under environmental realistic concentrations, and the

15 toxicity of the $\mathrm{Cu}-\mathrm{FA}$ exposure solution in the second bioassay should not be caused by

16 FA. Without FA in the exposure solution, copper was very toxic to the larvae (Fig. 4).

17 At $23 \mathrm{~g} \mathrm{l}^{-1}$ and higher copper concentrations, the percentage of abnormal larvae (19.5)

18 was significantly higher than that of the control $(2.5)(\mathrm{P}<0.05)$. When the dosage data 
1 (X) were transformed by $\log (\mathrm{X}+1)$, the dose-response curve displayed a sigmoid shape.

2 The data were fitted to Eq. (2). Because no larvae survived through the end of the

3 bioassay at the two highest copper concentrations, the maximum response of the model

4 was constrained to 100 . The minimum response was constrained to $>0$, instead of 0 , to

5 account for the presence of a small percentage of abnormal larvae in the copper-free

6 control. The fitting parameters are shown in Table 2 and the calculated $\mathrm{EC}_{50}$ was $55.6 \mathrm{~kg}$ $71^{-1}$.

8 With FA in the exposure solution, the toxicity curve was displaced to the right, and the

9 displacement increased with increasing FA concentration (Fig. 4A). At each FA

10 concentration, the fitting between percentage of abnormal larvae and total copper

11 concentration was quite satisfactory, with an $r^{2}$ higher than 0.98 (Table 2). The $\mathrm{EC}_{50}$

12 was $65.0 \mathrm{~g} \mathrm{l}^{-1}$ at $2.5 \mathrm{mg} \mathrm{l}^{-1} \mathrm{FA}, 75.3 \mathrm{~kg}^{-1}$ at $5 \mathrm{mg} \mathrm{l}^{-1} \mathrm{FA}, 103.0 \mathrm{~g} \mathrm{l}^{-1}$ at $10 \mathrm{mg} \mathrm{l}^{-1} \mathrm{FA}$ and

$13137.4 \mathrm{~kg}^{-1}$ at $20 \mathrm{mg} \mathrm{l}^{-1} \mathrm{FA}$. A comparison of the $\log \mathrm{EC}_{50}$ of the control and individual

14 FA treatments using $F$ test showed significant differences (Table 2). However, when

15 data from all FA treatments were combined and plotted against labile copper

16 concentration (Fig. 4B), the data could be fitted to Eq (2), with an $r^{2}$ of 0.986 and an $\mathrm{EC}_{50}$

17 of $58.9 \mathrm{~kg}^{-1}$. A comparison between the $\log \mathrm{EC}_{50}$ for all FA treatments and that for the

18 no-FA control by $F$ test showed no significant difference (Table 2). 
1 4. Discussion

2 In view of the experimental evidence accumulated in the 1960s and 70s that metal

3 toxicity is often related to the free ion concentration or inorganic complexes of the metal,

4 Morel (1983) formulated the free ion activity model (FIAM), which uses the free ion

5 activity as a predictor of metal toxicity in the presence of inorganic and organic

6 chemicals. The FIAM recognizes that many metals form complexes with inorganic and

7 organic chemicals both in solution and particulate forms in natural water and that such

8 complexation affects metal bioavailability and toxicity to aquatic organisms. Thus, it

9 emphasizes the importance of water chemistry, without taking into account of the

10 interaction among abiotic factors and between these factors and aquatic organisms.

11 Although many studies have lent support to the FIAM, a number of exceptions have

12 been found (review by Campbell, 1995). One exception involves tests of freshwater

13 organisms performed under varying $\mathrm{pH}$ or water hardness, where cations compete for the

14 metal binding site and reduce metal bioavailability (Pärt, Svanberg, \& Kiessling, 1985;

15 Meyer, Santore, Bobbitt, DeBrey, Boese, Paquin et al., 1999; Qiu, Xie, \& Wang, 2005).

16 Another exception occurs where, in the presence of DOM, metal bioavailability is higher

17 than the value predicted by the FIAM (Table 8 in Campbell, 1995; Voets et al., 2004),

18 being consistent with the observation that some DOM-metal complexes can be taken up 
1 by aquatic organisms (Tao, Liang, Liu, \& Xu, 1999; Roditi, Fisher, \& Sanudo-Wilhelmy,

2 2000; Pan \& Wang, 2004). The biotic ligand model (BLM) (Di Toro et al., 2001), which

3 predicts metal toxicity based on the amount of metal accumulated at presumptive binding

4 sites of aquatic organisms, assumes that metal ions in the water bind to a biotic ligand,

5 such as fish gill, and that the toxic effect occurs when the concentration of the

6 metal-biotic ligand reaches a threshold. Cations (i.e. $\mathrm{Ca}^{2+}, \mathrm{Mg}^{2+}, \mathrm{Na}^{+}$, and $\mathrm{H}^{+}$), anions

7 (i.e. $\mathrm{SO}_{4}{ }^{2-}$ and $\mathrm{Cl}^{-}$), DOM and suspended particulates in the water affect such binding,

8 thus changing metal bioavailability and toxicity. Thus, the BLM is an important

9 extension of the FIAM, which considers both water chemistry and biological responses

10 when predicting metal toxicity. This model has been successfully applied to predict

11 metal bioavailability to a number of freshwater organisms, such as cladocerans and fish

12 (Di Toro et al., 2001; Zhou et al., 2005), amphipods (Borgmann et al., 2005), earthworms

13 (Steenbergen et al., 2005) and algae (De Schamphelaere et al., 2005). However, its

14 application to coastal organisms has not been widely reported. A number of studies

15 appear to indicate water chemistry alone can be used to predict metal toxicity to

16 echinoderm larvae (Lorenzo et al., 2002; Rivera-Duarte et al., 2005), bivalve larvae

17 (Rivera-Duarte et al., 2005), and algae (Stauber et al., 2005), which support the

18 application of the FIAM in coastal waters. However, the situation is not straightforward, 
1 as Lorenzo et al. (2005) showed that, in a marine mussel, water chemistry alone can be

2 used to predict copper accumulated in the gills, but cannot be used to predict copper

3 accumulated in the whole body. Of course, given the few numbers of marine organisms

4 studied, it is premature to generalize whether the FIAM or BLM is only applicable to

5 certain groups of organisms.

6 H. elegans is a serpulid polychaete species commonly found in tropical and subtropical

7 waters. Our recent studies showed that larval development of this species was sensitive

8 to copper stress (Xie et al., 2005); addition of algae into the exposure medium reduced

9 aqueous copper concentration, and thus copper toxicity (Wong et al., 2006). In this

10 study, we quantified the effects of FA, an important component of DOM in natural waters,

11 on the toxicity of copper to the larvae. The results showed that FA was not toxic to the

12 larvae up to the highest concentration tested (256 $\left.\mathrm{mg} \mathrm{l}^{-1}\right)$, indicating FA is not toxic to the

13 larvae under environmentally realistic concentrations. Copper and FA binding reduced

14 ASV labile copper concentration, and such reaction could be quantified using a simple

15 ligand binding model. Although visual observation of the relationship between [CuL]

16 and $[\mathrm{CuL}] /\left[\mathrm{Cu}^{\prime}\right]$ in the Scatchard plot appeared linear, which indicated the presence of

17 one class of dominant binding sites, we explored the use of both one- and two-site

18 binding models because humic substances contain many functional groups, such as 
1 carboxylic and phenolic groups, the binding might be better described by a poly-site

2 model. In fact, two- to five-site models have been used by a number of authors (Hering

3 \& Morel, 1988; Cabaniss \& Shuman, 1988; Kim et al., 1999; Ma et al., 2002). Using a

4 three-site model to describe the binding between copper and humic acid, Hering \& Morel

5 (1988) found two stronger but less abundant ligands with $\log K^{\prime}$ exceeding 9 and a

6 weaker but more abundant ligand with a $\log K^{\prime}$ of 6.6. The ligand found in the one-site

7 model in Lorenzo et al. (2002) may thus correspond to the weaker ligand in Hering \&

8 Morel (1988). To evaluate whether a multi-site model was a better description of our

9 data, we also fitted the pooled data for all FA treatments to a two-site model, i.e. $\mathrm{n}=2$ in

10 Eq. (1). The result showed only a slightly improved $r^{2}(0.989)$ over the value for the

11 one-site model (0.979). The fitting parameters for the weaker ligand were: $\log K_{l}{ }^{\prime}=$

125.95 , with a $95 \%$ C.I. of 5.75 to 6.08 , and $\left[\mathrm{L}_{1}\right]=0.19$, with a $95 \%$ C.I. of 0.18 to 0.21 .

13 These values were very close to those predicted by the one site model (Table 1). For the

14 stronger ligand, $\left[\mathrm{L}_{2}\right]$ was 0.025 , with a $95 \%$ C.I. of 0.005 to 0.045 , and $K_{2}$ ' was $2.55 \mathrm{x}$

$1510^{7}$, with a $95 \%$ C.I. of 0 to $2.70 \times 10^{7} . \quad K_{2}$ ' had a very large confidence interval

16 indicating the estimated value was not reliable; therefore the two-site model was

17 inappropriate for our data.

18 An important result of Fig. 2 and Table 1 was that the fitting parameters for the 
1 one-site model were quite close within the range of FA concentrations tested, as was the

2 case in another study of copper binding by Suwannee River FA (Lund et al., 1990). This

3 consistency indicates aggregation and other structural changes in the FA were minimal in

4 the exposure system, and that a single set of $K^{\prime}$ and [L] could be used to predict labile

5 copper concentration across a relatively wide range of FA concentrations. One-site

6 binding model has been used in a number of studies of the binding between copper and

7 humic substances (Turner, Vaney, Whitfield, Manroura, \& Riley, 1987; Lund et al., 1990;

8 Lorenzo et al., 2002). In Lorenzo et al. (2002), the model was successfully applied to

9 describe the binding between humic acid (HA) and copper (Lorenzo et al. 2002), with an

$10 r^{2}$ of 0.993 . The [L] in Lorenzo et al. (2002) was $0.23 \mu \mathrm{mol}$ site $\mathrm{mg}^{-1} \mathrm{HA}$, being higher

11 than the value obtained from this study $(0.19 \mu \mathrm{mol}$ site $\mathrm{mg} \mathrm{C}$, equivalent to $0.10 \mu \mathrm{mol}$ site

$\left.12 \mathrm{mg}^{-1} \mathrm{FA}\right)$. The $\log K^{\prime}$ for HA (6.53) in Lorenzo et al. (2002) was also higher than the

13 value for FA from this study (6.19). A comparison of these binding parameters shows

14 that the binding of $\mathrm{Cu}-\mathrm{FA}$ is weaker than that of $\mathrm{Cu}-\mathrm{HA}$, being consistent with previous

15 reports (Stevenson, 1982). However, under different experimental conditions, $\log K^{\prime}$ for

16 copper complexation with natural water or fulvic acid can vary from 5.1 to 5.6 (Lund et

17 al., 1990) to 6.6 to 7.4 (Turner et al., 1987).

18 Although FA is not as strong as HA in terms of binding to copper, the modeling result 
1 showed that FA still greatly affected labile copper concentration. Assuming that FA

2 content of seawater reaches a level of $2 \mathrm{mg} \mathrm{l}^{-1}$ and a complexation capacity of $0.19 \mathrm{mmol}$

$3 \mathrm{Cu} \mathrm{g} \mathrm{C}^{-1}$ or $0.10 \mathrm{mmol} \mathrm{Cu} \mathrm{g}{ }^{-1} \mathrm{FA}$, the maximum concentration of cupric ion buffered by

4 the system can be estimated as follows:

$5 \quad 0.1 \mathrm{mmol} \mathrm{Cu} / 1000 \mathrm{mg} \mathrm{FA} \mathrm{x} 2 \mathrm{mg} \mathrm{FAl}^{-1}=0.2 \mu \mathrm{mol} \mathrm{Cu} . \quad 0.2 \mu \mathrm{mol} \mathrm{Cu}$ is equivalent to

$6 \quad 12.7 \mathrm{~g} \mathrm{l}^{-1}$ of $\mathrm{Cu}$. This simple calculation shows that when coastal water is used as

7 dilution water in laboratory bioassay, metal toxicity could be underestimated substantially.

8 Thus, albeit a weak ligand, FA could lead to an appreciable reduction in copper toxicity.

9 ASV labile copper has been widely used to correlate copper toxicity in the presence of

10 pure FA, synthetic ligands or in natural water (review by Florence 1986; Deaver \&

11 Rodgers, 1996; Wang et al. 2002; Rivera-Duarte et al., 2005; Stauber et al. 2005). As

12 noted by Florence (1986), when synthetic ligands such as nitrolotriacetic acid,

13 8-hydroxyquinoline or ethyl xanthogenate were present, ASV copper did not show a clear

14 relationship with toxicity. In natural water or synthetic water containing FA or HA, the

$15 \mathrm{pH}$ at which ASV measurements are made greatly affect the data because at low $\mathrm{pH}$ more

16 metal ions are labile. Srna, Garrett, Miller, \& Thum (1980) noted that ASV measured

17 ligands were about half of those that could result in the observed amelioration in copper

18 toxicity. They explained that this discrepancy might be due to the fact that the ASV 
1 measurements were taken at a $\mathrm{pH}$ of 4.8 , whereas the bioassays were conducted at a $\mathrm{pH}$

2 of 8 . Such differences in $\mathrm{pH}$ conditions should not be a problem in a number of recent

3 studies (Lorenzo et al., 2002; Rivera-Duarte et al., 2005; Stauber et al. 2005) conducted

4 in seawater as the ASV measurements as well as bioassays were performed at natural $\mathrm{pH}$

5 for seawater, following the speciation scheme proposed by Florence (1986). In all these

6 studies, ASV concentration was an accurate predictor of the toxicity of copper in the

7 presence of various concentrations of humic substances. In this study, we found copper

8 toxicity to be a function of labile rather than total metal concentrations, and the curve

9 fitting for the pooled data from all of the FA treatments was not significantly different

10 from that for the no-FA treatment. The toxicity of seawater samples containing FA was

11 thus dependent on labile copper rather than total copper concentration.

12 From these data we can conclude that FA is reactive with copper, fulvic acid at

13 environmentally realistic concentrations can have a protective effect on copper toxicity to

14 H. elegans larvae, and such effect can be predicted based on ASV labile copper. This

15 study extends the application of the FIAM in predicting copper toxicity to polychaete

16 larvae in seawater containing FA. It should be noted that the bioassays in this study

17 were conducted under constant salinity and temperature conditions, and the conditional

18 constants for the binding model were determined after allowing the $\mathrm{Cu}-\mathrm{FA}$ reaction to 
1 reach equilibrium, whereas in natural seawater, environmental parameters fluctuate and

2 the levels of FA and HA, as well as particulate organic matter change spatially and

3 temporally. Further studies should thus test the applicability of ASV in the prediction of

4 metal toxicity to $H$. elegans larvae in natural seawater of different complexation

5 capacities.

\section{Acknowledgements}

$7 \quad$ This project was supported by a FRG grant from HKBU to J.W.Q. X.T. and B.Z.

8 were exchange postgraduate students when conducting this research at HKBU. We

9 thank C.W. Chau for logistic support as well as assistance in a number of experiments,

10 N.C. Wong for assistance in voltammetry, K.Y. Chu for proofreading, and two

11 anonymous reviewers for helpful comments on the manuscript.

\section{References}

13 Allen, H.E., \& Hansen, D.J. (1996). The importance of trace metal speciation to water

14 quality criteria. Water Environmental Research, 68, 42-54.

15 Borgmann, U., Nowierski, M., \& Dixon, D.G. (2005). Effect of major ions on the toxicity

16 of copper to Hyalella azteca and implications for the biotic ligand model. Aquatic

$17 \quad$ Toxicology, 73, 268-287.

18 Bowen, H.J.M. (1985). The cycles of copper, silver and gold. In O. Hutzinger, The 
1

3 Buffle, J. (1984). Natural organic matter and metal-organic interactions in aquatic

4

handbook of environmental chemistry, vol. 1. The natural environment and the biogeochemical cycles (pp. 1-27). Berlin: Springer-Verlag. systems. In H. Siegel, Metal ions in biological systems. Circulation of metals in the environment (pp. 165-221). New York: Marcel Dekker.

Cabaniss, S.E., \& Shuman, M.S. (1988). Copper binding by dissolved organic matter: I.

7 Suwannee River fulvic acid equilibria. Geochimica et Cosmochimica Acta, 52,

$8 \quad 185-193$.

9 Campbell, P.G.C. (1995). Interactions between trace metals and aquatic organisms, a

critique of the free-ion activity model. In A. Tessier, D.R. Turner, Metal speciation

and bioavailability in aquatic systems. IUPAC series on analytical and physical

2 chemistry of environmental systems (pp. 45-102). New York: Wiley.

13 Chapman, G.A., Denton, D.L., \& Lazorchak, J.M. (1995). Short-term methods for

4 estimating the chronic toxicity of effluents and receiving waters to west coast marine

5 and estuarine organisms, 1st ed. EPA/600/R-95-136.

16 De Schamphelaere, K.A.C., Stauber, J.L., Wilde, K.L., Markich, S.J., Brown, P.L.,

7 Franklin, N.M., Creighton, N.M., \& Janssen, C.R. (2005). Toward a biotic ligand

8 model for freshwater green algae: Surface-bound and internal copper are better 
1

3 Deaver, E., \& Rodgers, J.H. Jr. (1996). Measuring bioavailable copper using anodic

predictors of toxicity than free $\mathrm{Cu}^{2+}$ ion activity when $\mathrm{pH}$ is varied. Environmental Science \& Technology, 39, 2067-2072. stripping voltammetry. Environmental Toxicology and Chemistry, 15, 1925-1930.

Di Toro, D.M., Allen, H.E., Bergman, H.L., Meyer, J.S., Paquin, P.R., \& Santore, R.C. (2001). A biotic ligand model of the acute toxicity of metals. I. Technical basis. Environmental Toxicology and Chemistry, 20, 2383-2396.

Florence, T.M. (1986). Electrochemical approaches to trace element speciation in waters. A Review. Analyst, 111, 489-505.

Harvey. D. (2000). Modern Analytical Chemistry. Singapore: McGraw-Hill Higher Education.

Hering, J.G., \& Morel, F.M.M. (1988). Humic acid complexation of calcium and copper. Environmental Science \& Technology 22, 1234-1237.

His, E., Beiras, R., \& Seaman, M.N.L. (1999). The assessment of marine pollution bioassays with bivalve embryos and larvae. In A.J. Southward, P.A. Tyler, C.M. Young, Advances in marine biology (pp. 1-178). San Diego: Academic Press.

Kim, S.D., Ma, H., Allen, H.E., \& Cha, D.K. (1999). Influence of dissolved organic matter on the toxicity of copper to Cerodaphnia dubia: effect of complexation 
kinetics. Environmental Toxicology and Chemistry, 18, 2433-2437.

2 Lorenzo, J.I., Nieto, O., \& Beiras, R. (2002). Effect of humic acids on speciation and

3 toxicity of copper to Paracentrotus lividus larvae in seawater. Aquatic Toxicology,

$4 \quad 58,27-41$.

5 Lorenzo, J.I., Beiras, R., Mubiana, V.K., \& Blust, R. (2005). Copper uptake by Mytilus

6 edulis in the presence of humic acids. Environmental Toxicology and Chemistry,

$7 \quad 24,973-980$.

8 Lund, W., Helbak, I.A., \& Seip, H.M. (1990). Studies of the complexation properties of

9 aquatic humic material by differencial pulse polarography. Science of the Total

$10 \quad$ Environment, 92, 269-281.

11 Ma, H., Kim, S.D., Cha, D.K., \& Allen, H.E. (1999). Effect of kinetics of complexation

12 by humic acid on toxicity of copper to Ceriodaphnia dubia. Environmental

13 Toxicology and Chemistry, 18, 828-837.

14 Meyer, J.S., Santore, R.C., Bobbitt, J.P., DeBrey, L.D., Boese, C.J., Paquin, P.R., Allen,

15 H.E., Bergman, H.L., \& Di Toro, D.M. (1999). Binding of nickel and copper to fish

16 gills predicts toxicity when water hardness varies, but free-ion activity does not.

17 Environmental Science and Technology, 33, 913-916.

18 Morel, F.M.M. (1983). Principles of aquatic chemistry. New York: Wiley. 
1 Motulsky, H.J., \& Christopoulos, A. (2003). Fitting models to biological data using linear and nonlinear regression. A practical guide to curve fitting. San Diego: GraphPad Software Inc.

4 Newell, A.D., \& Sanders, J.G. (1986). Relative copper binding capacities of dissolved organic compounds in a coastal-plain estuary. Environmental Science \& Technology, $20,817-821$.

7 Pan, J.F., \& Wang, W.X. (2004). Influences of dissolved and colloidal organic carbon on the uptake of $\mathrm{Ag}, \mathrm{Cd}$, and $\mathrm{Cr}$ by the marine mussel Perna viridis. Environmental Pollution, 129, 467-477.

10 Pärt, P., Svanberg, O., \& Kiessling, A. (1985). The availability of cadmium to perfused

11 rainbow trout gills in different water qualities. Water Research, 19, 427-434.

12 Pechenik, J.A., \& Qian, P.Y. (1998). Onset and maintenance of metamorphic competence

13 in the marine polychaete Hydroides elegans Haswell in response to three chemical cues. Journal of Experimental Marine Biology and Ecology, 226, 51-74.

15 Porta, A.A., \& Ronco, A.E. (1993). Cu(II) acute toxicity to the rotifer Branchionus calyciflorus, as affected by fulvic acids of freshwater origin. Environmental Pollution, 82, 263-267.

18 Qiu, J.W., \& Qian, P.Y. (1997). Combined effects of salinity, temperature and food on 

early development of the polychaete Hydeides elegans. Marine Ecology Progress Series, 152, 79-88.

3 Qiu, J.W., Xie, Z.C., \& Wang, W.X. (2005). Effects of calcium on the uptake and

4 elimination of cadmium and zinc in Asiatic clams. Archives of Environmental

5 Contamination and Toxicology, 48, 278-287.

6 Rivera-Duarte, I., Rosen, G., Lapota, G., Chadwick, D.B., Kear-Padilla, L., \& Zirino, A.

7 (2005). Copper toxicity to larval stages of three marine invertebrates and copper

8 complexation capacity in San Diego Bay, California. Environmental Science \&

$9 \quad$ Technology, 39, $1542-1546$.

10 Roditi, H.A., Fisher, N.S., \& Sanudo-Wilhelmy, S.A., 2000. Uptake of dissolved organic

11 carbon and trace elements by zebra mussels. Nature, 407, 78-80.

12 Ross, K.E., \& Bidwell, J.R. (2001). A 48-h larval development toxicity test using the

13 marine polychaete Galeolaria caespitosa Lamarck (Fam. Serpulidae). Archives of

14 Environmental Contamination and Toxicology, 40, 489-496.

15 Roy, R., \& Campbell, P.G.C. (1997). Decreased toxicity of Al to juvenile Atlantic salmon

16 (Salmo salar) in acidic soft water containing natural organic matter: a test of the

17 free-ion model. Environmental Toxicology and Chemistry, 16, 1962-1969.

18 Santore, R.C., Di Toro, D.M., Paquin, P.R., Allen, H.E., \& Meyer, J.S. (2001). A biotic 
1

4 Srna, R.F., Garrett, K.S., Miller, S.M., \& Thum, A.B. (1980). Copper complexation ligand model of the acute toxicity of metals. II. Application to acute copper toxicity in freshwater fish and daphnia. Environmental Toxicology and Chemistry, 20, $2397-2402$. capacity of marine water samples from southern California. Environmental Science \& Technology, 14, 1482-1486.

Stauber, J.L., Andrade, S., Ramirez, M., Adams, M., \& Correa, J.A. (2005). Copper bioavailability in a coastal environment of Northern Chile: Comparison of bioassay and analytical speciation approaches. Marine Pollution Bulletin, 50, 1363-1372.

Steenbergen, N.T.T.M., Iaccino, F., De Winkel, M., Reijnders, L., Peijnenburg, W.J.G.M. (2005). Development of a biotic ligand model and a regression model predicting acute copper toxicity to the earthworm Aporrectodea caliginosa. Environmental Science \& Technology 39, 5694-5702.

Stevenson, F.J. (1982). Humus chemistry. Genesis, composition, reactions. New York: John Wiley \& Sons.

Tao, S., Liang, T., Liu, C., \& Xu, S. (1999). Uptake of copper by neon tetras (Paracheirodon innesi) in the presence and absence of particulate and humic matter. Ecotoxicology, 8, 269-275. 
1 Thurman, E.M. (1985). Organic geochemistry of natural waters. Boston: Martinus

2 Nijhoff/Dr. W. Junk Publishers.

3 Turner, D.R., Varney, M.S., Whitfield, M., Mantoura, R.F.C., \& Riley, J.P. (1986).

4 Electrochemical studies of copper and lead complexation by fulvic acid. I.

5 Potentiometric measurements and a critical comparison of metal binding models.

6 Geochimia et Cosmochimia Acta, 50, 289-297.

7 Turner, D.R., Varney, M.S., Whitfield, M., Mantoura, R.F.C., \& Riley, J.P. (1987).

8 Electrochemical studies of copper and lead complexation by fulvic acid. II. A

9 critical comparision of potentiometric and polarographic measurements. Science of

10 the Total Environment, 60, 17-34.

11 Van Ginneken, L., Bervoets, L., \& Blust, R. (2001). Bioavailability of Cd to the common

12 carp, Cyprinus carpio, in the presence of humic acid. Aquatic Toxicology, 52, 13-27.

13 Voets, J., Bervoets, L., \& Blust, R., 2004. Cadmium bioavailability and accumulation in

14 the presence of humic acid to the zebra mussel, Dreissena polymorpha.

15 Environmental Science and Technology, 38, 1003-1008.

16 Wang, Z., Huang, S., \& Liu, Q. (2002). Use of anodic stripping voltammetry in predicting

17 toxicity of copper in river water. Environmental Toxicology and Chemistry, 21,

$18 \quad 1788-1795$. 
1 White, S.L., \& Rainbow, P.S. (1985). On the metabolic requirements for copper and zinc

2 in molluscs and crustaceans. Marine Environmental Research, 160, 215-229.

3 Wong, N.C., Wong, M.H., Shiu, K.K., Qiu, J.W. (2006). Dependency of copper toxicity

4 to polychaete larvae on algal concentration. Aquatic Toxicology, 77, 117-125.

5 Xie, Z.C., Wong, N.C., Qian, P.Y., Qiu, J.W. (2005). Responses of polychaete Hydroides

6 elegans life stages to copper stress. Marine Ecology Progress Series, 285, 89-96.

7 Zhou, B., Nichols, J., Playle, R.C., \& Wood, C.M. (2005). An in vitro biotic ligand model

8 (BLM) for silver binding to cultured gill epithelia of freshwater rainbow trout

9 (Oncorhynchus mykiss). Toxicology and Applied Pharmacology, 202, 25-37.

10 
2 Table 1. Fitting parameters for the binding between copper and fulvic acid in artificial seawater as estimated by a one-site binding model.

$3[\mathrm{~L}]$ is ligand concentration in $\mu \mathrm{mol}$ site $\mathrm{mg}^{-1} \mathrm{C}$, and $K^{\prime}$ is conditional stability constant. Data in parentheses are $95 \%$ confidence

4 intervals.

5

\begin{tabular}{ccccc}
\hline Treatment & \multicolumn{1}{c}{$\log K^{\prime}$} & {$[\mathrm{L}]$} & $d f$ & $r^{2}$ \\
\hline $8 \mathrm{mg} \mathrm{FA} \mathrm{l}^{-1}$ & $6.154(6.076$ to 6.249$)$ & $0.203(0.190$ to 0.216$)$ & 14 & 0.989 \\
$16 \mathrm{mg} \mathrm{FA} \mathrm{l}^{-1}$ & $6.172(6.089$ to 6.274$)$ & $0.197(0.183$ to 0.212$)$ & 14 & 0.988 \\
$32 \mathrm{mg} \mathrm{FA} \mathrm{l}^{-1}$ & $6.363(6.309$ to 6.424$)$ & $0.162(0.153$ to 0.169$)$ & 14 & 0.996 \\
$64 \mathrm{mg} \mathrm{FA} \mathrm{l}^{-1}$ & $6.663(6.595$ to 6.744$)$ & $0.112(0.105$ to 0.119$)$ & 14 & 0.992 \\
All data & $6.186(6.137$ to 6.240$)$ & $0.194(0.185$ to 0.203$)$ & 59 & 0.979 \\
\hline
\end{tabular}


2 Table 2. Fitting parameters for Fig. 4. Percentage of abnormal larvae was expressed as a function of total (A) or labile (B) copper

3 concentration. Data in parentheses are 95\% confidence intervals. Data in the $F$ and P columns are results of $F$ test that compares the

$4 \log \mathrm{EC}_{50}$ of a FA treatment and the control. A P value of $<0.05$ indicates significant difference.

5

\begin{tabular}{|c|c|c|c|c|c|c|c|c|}
\hline Figure & Treatment & Copper & $\log \mathrm{EC}_{50}$ & Hill slope & Baseline & $r^{2}$ & $F$ & $\mathrm{P}$ \\
\hline $4 \mathrm{~A}$ & Control & Total & 1.745 (1.694 to 1.795$)$ & $2.843(2.058$ to 3.628$)$ & $5.300(0$ to 11.680$)$ & 0.990 & & \\
\hline $4 \mathrm{~A}$ & 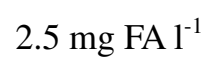 & Total & $1.813(1.789$ to 1.837$)$ & $2.900(2.509$ to 3.291$)$ & $2.380(0$ to 5.411$)$ & 0.997 & 7.32 & 0.0145 \\
\hline $4 \mathrm{~A}$ & $5 \mathrm{mg} \mathrm{FA}^{-1}$ & Total & 1.877 (1.818 to 1.935$)$ & $2.290(1.717$ to 2.873$)$ & 0.673 (0 to 7.343$)$ & 0.988 & 17.25 & 0.0006 \\
\hline $4 \mathrm{~A}$ & $10 \mathrm{mg} \mathrm{FAl}^{-1}$ & Total & $2.013(1.967$ to 2.060$)$ & 2.634 (2.001 to 3.268$)$ & $5.597(0.714$ to 10.480$)$ & 0.990 & 71.59 & $<0.0001$ \\
\hline $4 \mathrm{~A}$ & $20 \mathrm{mg} \mathrm{FAl}^{-1}$ & Total & 2.138 (2.085 to 2.192$)$ & $3.124(2.085$ to 4.164$)$ & 3.591 (0 to 9.331$)$ & 0.980 & 133.80 & $<0.0001$ \\
\hline $4 B$ & All FA data & Labile & $1.770(1.742$ to 1.797$)$ & $2.189(1.937$ to 2.441$)$ & $2.839(0.295$ to 5.383$)$ & 0.986 & 0.80 & 0.374 \\
\hline
\end{tabular}




\section{Figure captions}

2 Fig. 1. Binding between fulvic acid (FA) and copper. (A), For each total copper

Fig. 2. Relationship between ASV labile copper and normalized bound copper on concentration ranging from 16 to $256 \mathrm{~g} \mathrm{l}^{-1}$, the line shows a decline in labile copper concentration with increasing FA concentration. (B), Scatchard plot, showing a linear relationship for each of the four FA treatments $\left(64 \mathrm{mg} \mathrm{FAl} \mathrm{I}^{-1}\right.$ : $\mathrm{Y}=19.543-5.539 \mathrm{X}, r^{2}=0.966 ; 32 \mathrm{mg} \mathrm{FAl}^{-1}: \mathrm{Y}=7.084-2.778 \mathrm{X}, r^{2}=$ $0.961 ; 16 \mathrm{mg} \mathrm{FA}^{-1}: \mathrm{Y}=2.682-1.681 \mathrm{X}, r^{2}=0.914 ; 8 \mathrm{mg} \mathrm{FA}^{-1}: \mathrm{Y}=$ $\left.1.494-1.889 \mathrm{X}, r^{2}=0.868\right)$.

Fig. 3. Relationship between predicted (X) and measured (Y) ASV labile copper model.

Fig. 4. Percentage of abnormal larvae as a function of total (A) and labile (B) copper concentration. The bioassay data are mean \pm S.D. of four replicates. In (A), regression was performed for individual FA treatments. In (B), the solid line shows regression for the no-FA treatment, whereas the dash line shows the regression for the pooled data from all FA treatments. 

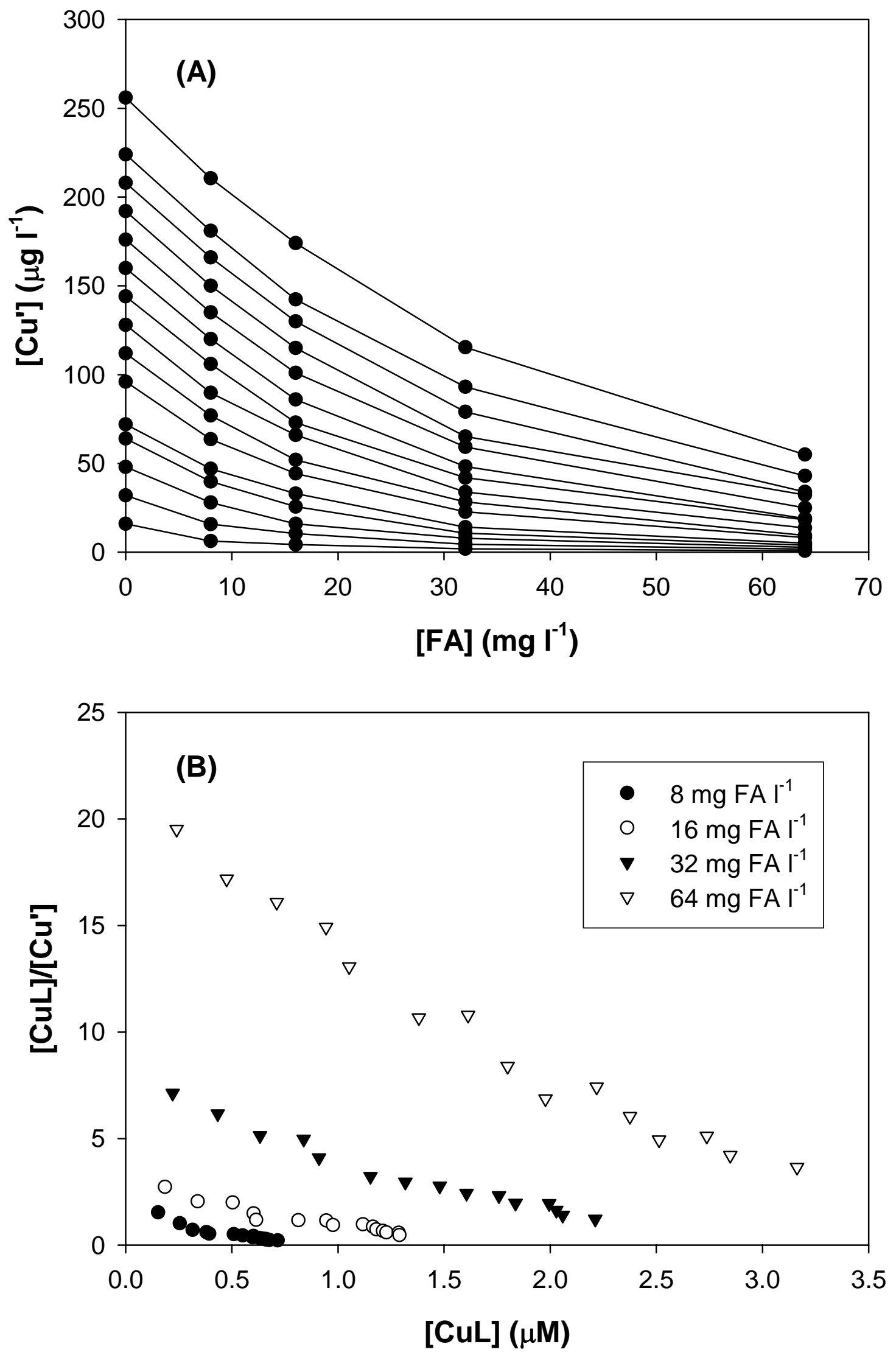

Fig. 1 


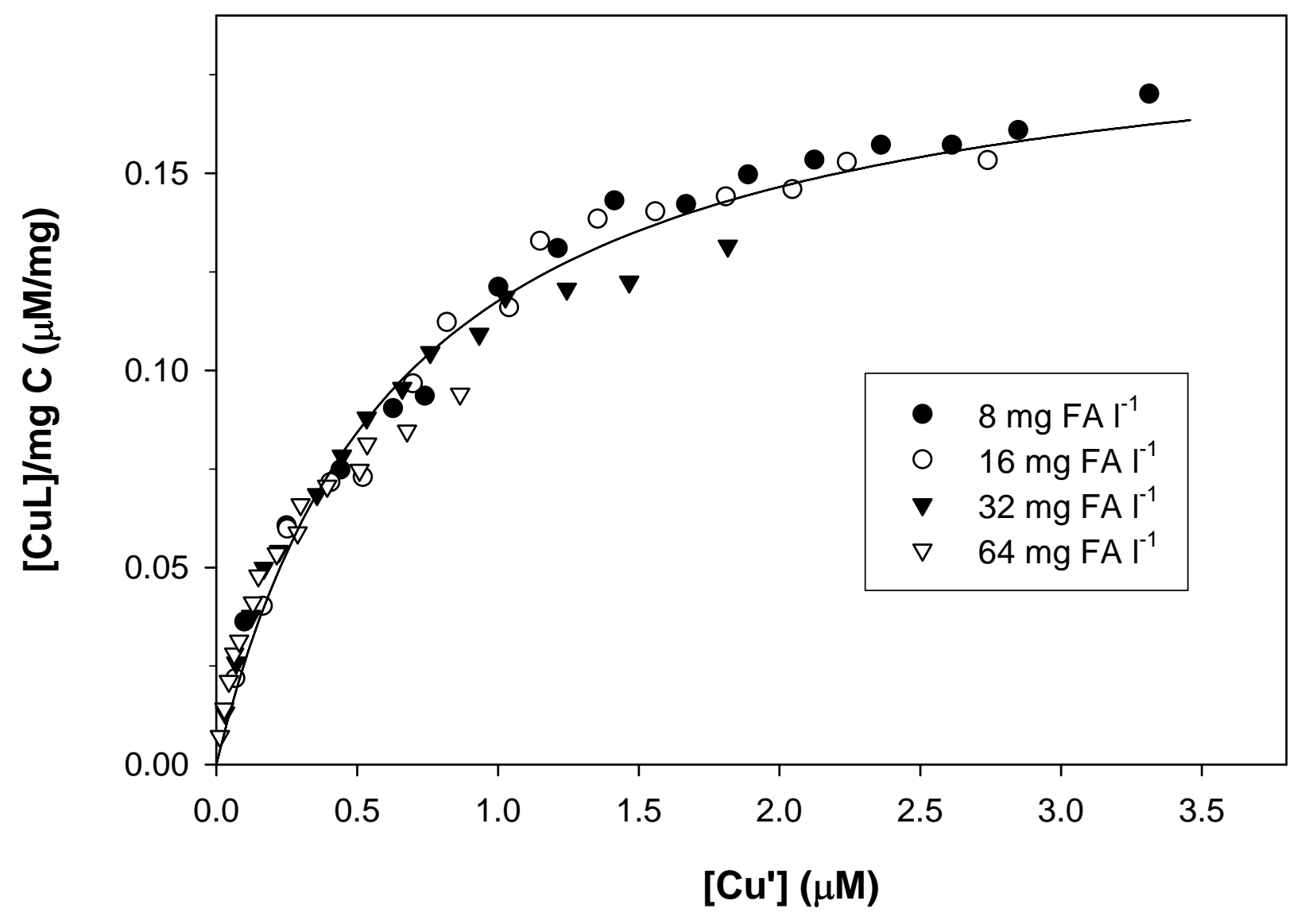

Fig. 2 


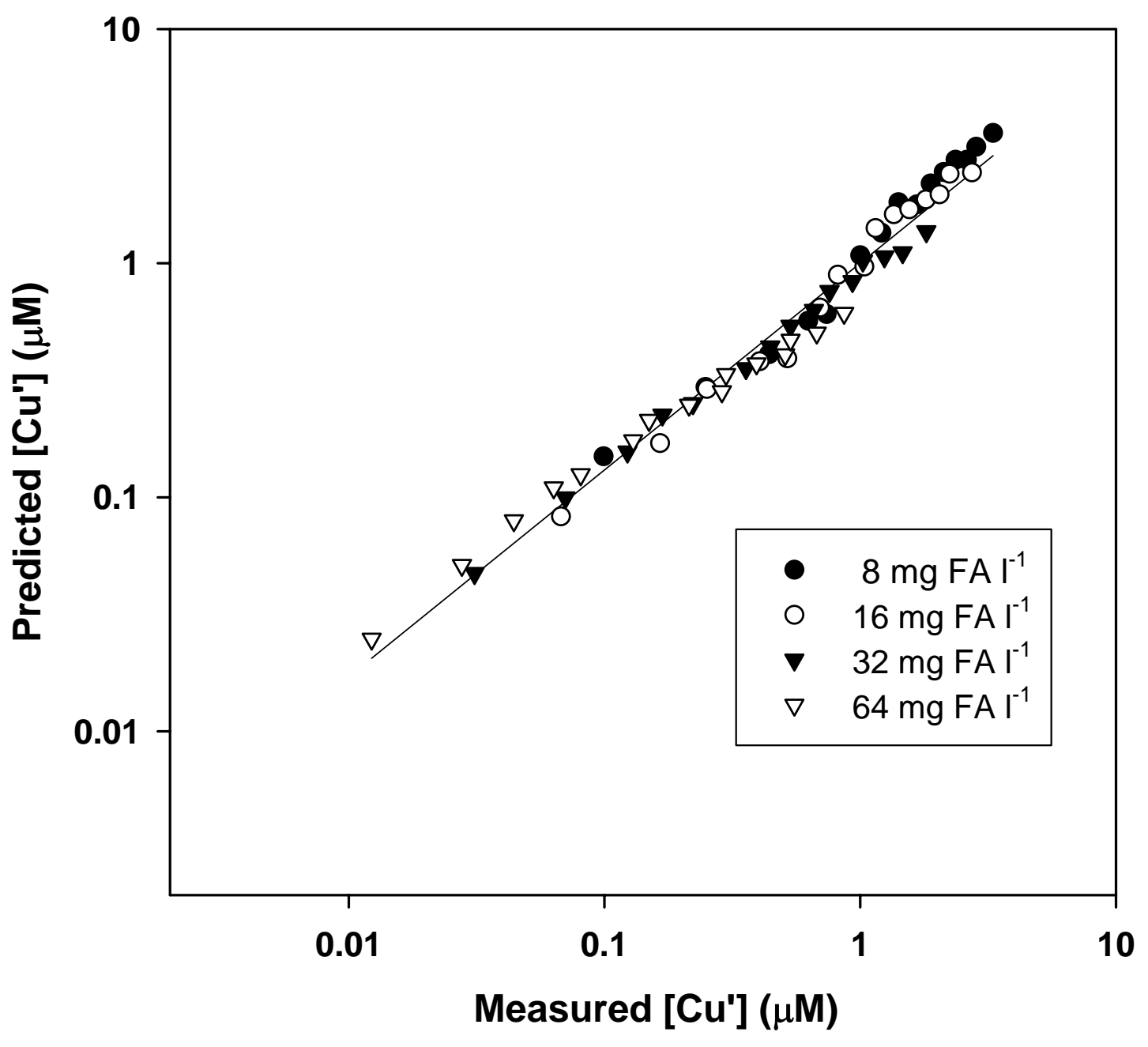

Fig. 3 

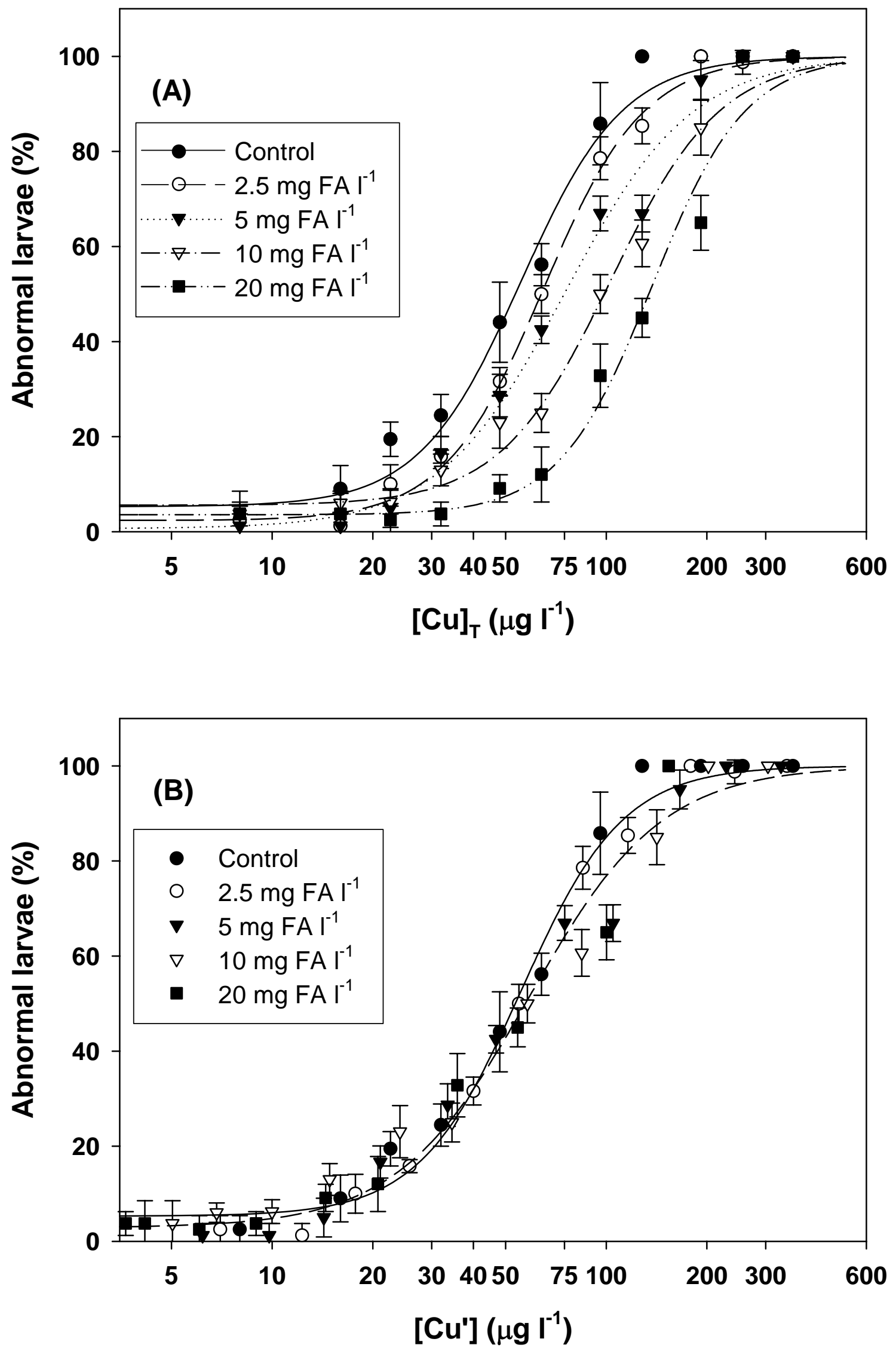

Fig. 4 